\title{
VISUALISING SYSTEMS: MAPPING SYSTEM FEATURES AND INTERACTIVE INFORMATION VISUALISATIONS IN DESIGN
}

\author{
A. Idrissov ${ }^{1, \otimes}$, S. Škec ${ }^{2}$ and A. M. Maier ${ }^{1}$ \\ ${ }^{1}$ DTU-Technical University of Denmark, Denmark, ${ }^{2}$ University of Zagreb, Croatia \\ $\triangle$ agzid@dtu.dk
}

\begin{abstract}
Interactive computer-supported information visualisations are being increasingly used in design. However, while there are frameworks that discuss how traditional representations, such as sketches, CAD models and static diagrams support design tasks, no such mapping exists for interactive visualisations of product-related information. As novel contributions, this paper reviews the design literature for the use of information visualisations. Moreover, using systems theory and Gestalt principles, insights on the applicability of such information visualisations for various design tasks are given.
\end{abstract}

Keywords: visualisation, systems engineering (SE), product design, product architecture, modelbased engineering

\section{Introduction}

Engineering design is a non-trivial problem-solving process, where complexity can originate from multiple factors. First, the amount and variety of product-related information, such as engineering requirements, component properties and simulation tests that designers have to make sense of are often large (Chandrasegaran et al., 2013). Second, designed products often span multiple design domains, such as software, hardware and electrical systems, which have to be integrated. Third, product-related information is dynamic, where changes become hard to track once the number of elements in a system becomes large. Therefore, design support methods that facilitate holistic understanding of complex product-related information are necessary.

Visual representations are an integral part of design in practice that facilitate such a holistic understanding of complex systems. They serve as conscription devices (Henderson, 1998), flexible enough for the incorporation of various inputs from multiple design participants and structured enough for individual use by designers. In essence, visual representations are "the glue that holds the entire design process together" (Henderson, 1998). In particular, during the initial design conceptualisation phases, sketching and other paper-based visual representations are typically used (Goldschmidt, 1991). With the evolution of digital media, however, computerised methods are becoming more prominent in the design process and are increasingly used in mixed-media environments combined with sketching and other paper or physical representations (Oxman, 2006).

This brings us to the field of information visualisation. Information visualisations defined as "computer-supported, interactive, visual representations of data" (Card et al., 1999). Due to their abilities to facilitate information retrieval, to assist information search and to aid visual recognition of 
patterns (Chen and Yu, 2000), such information visualisations are being increasingly used in organisations (Hashem et al., 2015). Despite a growing adoption of information visualisations in design practice, we note the lack of corresponding theoretical frameworks in the design research literature that would guide the incorporation of information visualisations into design support tools. Designers handle a wide variety of product-related information to perform corresponding design tasks, such as requirement traceability (Pavković et al., 2013) or optimising the modular structure of a product (Gumpinger et al., 2011). Therefore, the absence of such guidance on how to integrate information visualisations into design support tools means repetitions of the cumbersome process of continually generating new and ad-hoc visualisations for each specific task. This limits the acceptance and reusability of information visualisations in the design practice.

Although there are works that propose taxonomies of visual representations in the design literature (Bresciani, 2019; Chandrasegaran et al., 2013; Lengler and Eppler, 2007), none of them connect computer-supported information visualisations to design tasks. Thus, this paper presents an overview that links together information visualisations in product design and fundamental systems features, such as relationships, hierarchies, patterns and processes. By examining the Gestalt principles that enable visualising these system features, we discuss how computer-supported information visualisations facilitate visual representation of system features.

The paper starts with an overview of design representations and information visualisation theory. Second, we discuss current applications of information visualisations in design practice, focusing on the underlying Gestalt principles (Koffka, 2013) and computer-supported visualisation techniques. Third, we classify information visualisations according to fundamental system features and supported tasks in design. Finally, the paper concludes by discussing the implications of the study.

\section{Background}

\subsection{Design representations}

According to Ullman (1992), design can be described through three significant factors: design problems, the environment and the process. Design problems are characterised by their initial and final states, as well as satisfaction criteria. The design environment describes where design is taking place and consists of design participants, their characteristics and the resources they have. Finally, the design process involves a plan to solve the design problem, related action, observed effect and failure action.

Multiple visual representations with various purposes are used to represent such factors in design. Buur and Andreasen (1990) note that visual representations in design have various degrees of abstraction (e.g. 2D drawing vs 3D CAD model) and detail (rough 2D sketch vs detailed CAD drawing). Chandrasegaran et al. (2013) provide a taxonomy of representations in product design divided into five categories with the corresponding examples, as illustrated in Table 1:

Table 1. Visual representations in product design (adapted from

Chandrasegaran et al., 2013)

\begin{tabular}{|c|c|c|c|c|}
\hline Pictorial & Symbolic & Linguistic & Virtual & Algorithmic \\
\hline $\begin{array}{c}\text { sketches, } \\
\text { photographs }\end{array}$ & $\begin{array}{c}\text { entity-relationship } \\
\text { diagrams, flow } \\
\text { charts, decision } \\
\text { tables }\end{array}$ & $\begin{array}{c}\text { requirements, } \\
\text { design rules, } \\
\text { heuristics, verbal } \\
\text { communication }\end{array}$ & $\begin{array}{c}\text { virtual prototypes, } \\
\text { CAD models, CAE } \\
\text { simulations }\end{array}$ & $\begin{array}{c}\text { mathematical } \\
\text { equations, } \\
\text { algorithms, design } \\
\text { procedures }\end{array}$ \\
\hline
\end{tabular}

Engineering requirements are examples of an initial state of the design problems that are typically represented through linguistic representations, such as verbal communication or a textual checklist. Based on these requirements, designers then create pictorial and virtual representations of the final state of the design problem (Ullman, 1992), i.e. of the components that satisfy the given requirements. For instance, freehand sketches appear suitable as quick and flexible means for exploring the space of potential solutions (Goldschmidt, 1991). On the other extreme, CAD models and virtual prototypes 
serve as high-precision documents used for building the product. Algorithmic representations, such as equations, are commonly used to describe physical behaviour in the product (e.g. the Bernoulli equation to describe airflow).

Moreover, symbolic representations allow designers to abstract from the detailed product-related information and focus only on its essential aspects. For this reason, they are widely used to provide abstractions for all three factors. For instance, the entity-relationship diagrams are utilised to visualise the product architecture, i.e. the arrangement of components and interactions between them. However, visualising such product-related information for complex products becomes non-trivial, as, due to edge crossings and visual clutter, entity-relationships diagrams become less readable once the number of elements in the system becomes large (Maier et al., 2014).

Computer-supported, interactive information visualisations provide one way to reduce visual overload. Card et al. (1999) mention six critical benefits of information visualisations to support cognition, namely they: 1) enhance memory and processing capabilities 2) accelerate information search 3) allow detection of patterns 4) allow perceptual inference operators 5) facilitate monitoring 6) use a versatile medium to represent information. Naturally, taking advantage of such benefits is crucial in a complex problem-solving process such as design. Therefore, in the next section, we review the applications of interactive information visualisations in the design literature.

\subsection{Information visualisations}

Several studies in the engineering design literature report on the use of computer-supported information visualisations. For example, fish-eye visualisations are employed to represent change propagation during the design of helicopters (Keller et al., 2005). Another prominent visualisation is the parallel coordinates plot (Inselberg, 1985). Elbeltagi et al. (2017) show how an interactive parallel coordinates plot assists the evaluation of various building design alternatives concerning their energy efficiency. The use of treemap diagrams (Shneiderman, 1992) for aircraft wing design was studied in Yan et al. (2012). Interactive tree diagrams are, for example, also employed in the Design Rationale Editor tool (Bracewell et al., 2009) to illustrate alternatives during the design of a turbofan engine.

These information visualisations are some of many, selected for their frequent use in design, which is a problem-solving process. As Eppler and Platts (2009) highlight, there are cognitive challenges in the problem-solving process that are facilitated using information visualisations. Such challenges may include information overload, fixation on old perspectives and diverging views about systems.

At the core of interactive information visualisations (also widely applied in static symbolic visualisations) are eight Gestalt principles (Koffka, 2013; Ware, 2012). These principles provide a way to visually encode presented information to improve its understanding by the users:

- Proximity. Elements that are located close to each other are perceived to be in one group.

- Similarity. Elements that look alike are perceived to be members of one group.

- Connectedness. Linked elements (e.g. through a line) are perceived to have a relationship.

- Continuity. Connections between elements are more easily traced if they are smooth and continuous. For instance, entity-relationship diagrams are easier to read, when the edges between nodes have a smooth curvature compared to orthogonal edges.

- Symmetry. Elements that are symmetrical to each other are perceived to be members of one group.

- Closure. All elements within a closed contour element are perceived as children of that element.

- Relative size. Smaller elements within larger elements are perceived as separate objects

- Common fate. Elements moving in the same direction are perceived to be members of one group.

In addition to Gestalt principles, computer-supported information visualisations have two fundamental properties that enable the efficient presentation of complex information: rearrangement and interactivity (Spence, 2001). By rearranging the elements of the visualisation on demand, the information already presented can be viewed from multiple angles. For instance, in the co-occurrence matrix, rearrangement of rows and columns aids uncovering of groups (clusters) of elements that are 
highly interconnected. Interactivity is driven by users and allows them to change the visualisation according to their needs: e.g. by zooming in and out from "overview to details" (Shneiderman, 2003) or filtering out unnecessary elements.

Typically, information visualisations combine rearrangement and interactivity in multiple ways that result in various techniques. For instance, highlighting is a technique, where the elements of interest (e.g. nodes and edges of a graph that are selected by the user) change the colour intensity or line thickness to emphasise their importance compared to the rest of the elements. The collapsible tree (Plaisant et al., 2002) is another visual technique where selecting a parent node causes hiding of all child nodes, thereby reducing visual clutter. The coordinated views technique (Baldonado et al., 2000) consists of multiple visualisations presented in a unified display, where elements of each visualisation are synchronised to represent a single phenomenon from different aspects.

While these information visualisation techniques are widely used in visualising product-related information (Hashem et al., 2015), it is often not discussed why these specific visualisations were chosen to support particular design tasks. Several studies provide taxonomies of visualisations in design (Bresciani, 2019; Lengler and Eppler, 2007), yet none of those explicitly links computersupported information visualisations to design tasks through underlying visual principles. Having such linkage is crucial, as it allows one to incorporate information visualisations into design support tools in an informed manner. We address this gap by reviewing the use of information visualisations in design through the prism of fundamental features of complex systems. We employ systems theory and Gestalt principles to understand how information visualisations facilitate the performance of the design task at hand.

\section{System features and their representations}

When creating visualisations to represent certain phenomena, including product-related information, one needs to abstract from the context where the visualisation is applied (e.g. a task could be optimising product modularisation) and to look for some fundamental underlying features of what is being designed. One of the ways to achieve this is by seeing a designed product as a system, "a set of interacting components - technical artefacts - with well-defined behaviour and a well-defined function or purpose" (De Weck et al., 2011). Designing of systems, i.e. systems architecting, has found numerous applications in design and manufacturing, software engineering, urban planning, public policy modelling, etc. (Maier and Rechtin, 2000). Having reviewed design and systems research literature (Browning, 2009; Crawley et al., 2015; Maier and Rechtin, 2000; Simon, 1965), the following system features that were most frequently encountered in the literature are:

- relationships (interactions) between system entities,

- hierarchies,

- patterns, and

- processes.

Though this is not an exhaustive list of system features and they are not necessarily mutually exclusive (e.g. a hierarchy involves a set of relationships), systems features represent domain-independent and fundamental aspects of designed systems. By being able to characterise these fundamental aspects during performing design tasks, system features provide a backbone to the choice of information visualisation techniques - one can use information visualisations as "building blocks" to represent complex systems in a concise and informative manner.

By reviewing existing taxonomies of information visualisations (Keim, 2002; Shneiderman, 2003; Heer et al., 2010; Ribecca, 2015; Lengler and Eppler, 2007), we have linked the defined system features to information visualisations they represent. To find examples of information visualisations in design, we have conducted a literature search across Scopus and Google Scholar databases in two modes. To begin, we used the search query "information visualisation AND engineering design". Then, we replaced the term "information visualisation" in the search query with type names of information visualisations from the above taxonomies (e.g. "parallel coordinates plot") and their known synonyms. Table 2 illustrates the most frequently encountered examples of information 
visualisations according to the represented systems features, Gestalt principles (Koffka, 2013), and design tasks.

Table 2. Information visualisations and system features

\begin{tabular}{|c|c|c|c|}
\hline $\begin{array}{l}\text { Information } \\
\text { Visualisations }\end{array}$ & $\begin{array}{l}\text { System } \\
\text { Features }\end{array}$ & $\begin{array}{l}\text { Gestalt } \\
\text { principles } \\
\text { (Koffka, 2013) } \\
\end{array}$ & Design Tasks \\
\hline \multirow{2}{*}{$\begin{array}{l}\text { Co-occurrence matrix } \\
\text { (Steward, 1981) }\end{array}$} & \multirow{2}{*}{$\begin{array}{l}\text { Relationships, } \\
\text { Patterns }\end{array}$} & \multirow{2}{*}{$\begin{array}{l}\text { Continuity, } \\
\text { Proximity, } \\
\text { Similarity }\end{array}$} & Modularisation (van Beek et al., 2010) \\
\hline & & & Change propagation (Clarkson et al., 2004) \\
\hline \multirow{2}{*}{$\begin{array}{l}\text { Parallel coordinates plot } \\
\text { (Inselberg, 1985) }\end{array}$} & \multirow{2}{*}{$\begin{array}{l}\text { Relationships, } \\
\text { Patterns }\end{array}$} & \multirow{2}{*}{$\begin{array}{l}\text { Continuity, } \\
\text { Proximity, } \\
\text { Similarity }\end{array}$} & Multicriteria optimisation (Fleming et al., 2005) \\
\hline & & & Material selection (Elbeltagi et al., 2017) \\
\hline $\begin{array}{l}\text { Coordinated multiple } \\
\text { views (Baldonado et al., } \\
2000)\end{array}$ & Relationships & & $\begin{array}{l}\text { Comparison of design alternatives (Loos \& } \\
\text { Laet, 2016) }\end{array}$ \\
\hline \multirow[t]{2}{*}{ Tree diagram } & \multirow[t]{2}{*}{$\begin{array}{l}\text { Relationships, } \\
\text { Hierarchy }\end{array}$} & \multirow{2}{*}{$\begin{array}{l}\text { Closure, } \\
\text { Connectedness, } \\
\text { Continuity }\end{array}$} & $\begin{array}{l}\text { Documentation of design decisions (Bracewell } \\
\text { et al., 2009) }\end{array}$ \\
\hline & & & Modularisation (Van Beek et al., 2010) \\
\hline \multirow[t]{3}{*}{$\begin{array}{l}\text { Treemap (Shneiderman, } \\
\text { 1992) }\end{array}$} & \multirow[t]{3}{*}{$\begin{array}{l}\text { Hierarchy, } \\
\text { Patterns }\end{array}$} & \multirow{3}{*}{$\begin{array}{l}\text { Closure, } \\
\text { Proximity, } \\
\text { Similarity }\end{array}$} & $\begin{array}{l}\text { Comparison of design alternatives (Yan et al., } \\
\text { 2012) }\end{array}$ \\
\hline & & & Design reuse (Demian and Fruchter, 2006) \\
\hline & & & Modularisation (Gumpinger et al., 2011) \\
\hline Network diagram & $\begin{array}{l}\text { Relationships, } \\
\text { Hierarchy } \\
\text { Processes }\end{array}$ & $\begin{array}{l}\text { Closure, } \\
\text { Connectedness, } \\
\text { Continuity }\end{array}$ & Traceability (Martinec and Pavković, 2014) \\
\hline Scatter plot & $\begin{array}{l}\text { Relationships, } \\
\text { Patterns }\end{array}$ & $\begin{array}{l}\text { Closure, } \\
\text { Proximity, } \\
\text { Similarity, } \\
\text { Relative size }\end{array}$ & $\begin{array}{l}\text { Comparison of design alternatives (Yan et al., } \\
\text { 2012) }\end{array}$ \\
\hline Heatmap & Patterns & Similarity & Validation (Feldt et al., 2013) \\
\hline \multirow[t]{2}{*}{$\begin{array}{l}\text { Chord diagram / } \\
\text { hierarchical edge bundling }\end{array}$} & \multirow[t]{2}{*}{$\begin{array}{l}\text { Relationships, } \\
\text { Patterns }\end{array}$} & \multirow[t]{2}{*}{$\begin{array}{l}\text { Closure, } \\
\text { Connectedness }\end{array}$} & $\begin{array}{l}\text { Concept generation (Eppler and Kernbach, } \\
\text { 2016) }\end{array}$ \\
\hline & & & Traceability (Merten et al., 2011) \\
\hline \multirow[t]{3}{*}{ Sunburst diagram } & \multirow{3}{*}{$\begin{array}{l}\text { Hierarchy, } \\
\text { Patterns }\end{array}$} & \multirow{3}{*}{$\begin{array}{l}\text { Closure, } \\
\text { Proximity, } \\
\text { Similarity }\end{array}$} & Traceability (Merten et al., 2011) \\
\hline & & & System overview (Langelier et al., 2005) \\
\hline & & & Design reuse (Josefsson, 2014) \\
\hline $\begin{array}{l}\text { Sankey diagram } \\
\text { (Riehmann et al., 2005) }\end{array}$ & $\begin{array}{l}\text { Processes, } \\
\text { Relationships }\end{array}$ & $\begin{array}{l}\text { Continuity, } \\
\text { Common Fate }\end{array}$ & Traceability (Eppler and Kernbach, 2016) \\
\hline Gantt chart & Processes & $\begin{array}{l}\text { Closure, } \\
\text { Proximity }\end{array}$ & Task scheduling (Keller et al., 2006) \\
\hline
\end{tabular}

In what follows, we discuss definitions for each system feature, their manifestations in engineering design, current visual representations and their underlying Gestalt principles. Then, examples and properties of information visualisations that enable the representation of these features are given.

\subsection{Relationships}

"Relationships among elements are what give systems their added value" states Rechtin (1991). Similarly, Simon in his definition of complex systems argues that having a large number of elements is necessary but not enough to consider a system as complex. A system has to have elements that "interact in a non-simple way" to be complex (Simon, 1965) by exchanging energy, matter or information through various channels (Pahl et al., 2007). Following an example from (Ulrich and Eppinger, 2016, p.198), consider an interaction graph for a printer, where subsystems (e.g. enclosure, 
paper tray, printing mechanism, logic board) are connected by interactions which have to be taken into account during design - e.g. vibrations from the paper tray may affect printing cartridge. Moreover, such understanding of relationships is needed not only on the level of physical components but also between other product-related information, e.g. between components and the requirements they satisfy (Pavković et al., 2013). In design, relationships between elements are conventionally represented by entity-relationship diagrams (Figure 1a). In these diagrams, first, the Gestalt principle of closure is enabled when each entity has a contour and thusly becomes separated from other entities. Second, the connectedness is enabled when edges are drawn between entities. Third, the principle of continuity advises using smooth lines to improve readability. However, entity-relationship diagrams become harder to interpret once the number of elements and interactions between them grows (Maier et al., 2014).

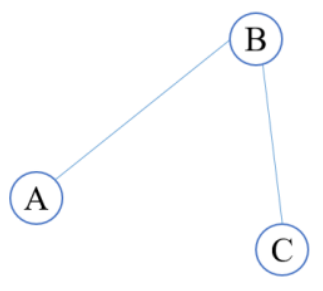

a) entity-relationship diagram

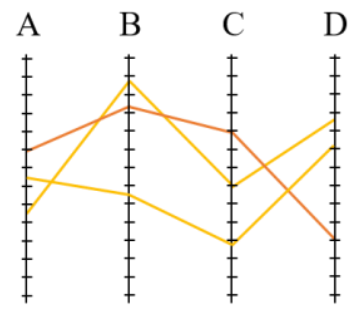

b) parallel coordinates plot

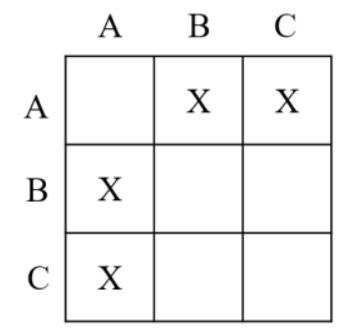

c) co-occurrence matrix

Figure 1. Visual representations of relationships

Information visualisations reduce visual clutter by allowing users to interactively explore relationships between elements, hiding and displaying layers of information or whole subsystems when necessary. For instance, if product architecture is visualised via such a diagram when interacting with a node (e.g. clicking the mouse on it or touching in a tablet device), edges that are connected to that node can be highlighted with a different colour (Idrissov et al., 2019). In addition to interactive entity-relationship diagrams, interactive co-occurrence matrices (Figure 1c) or parallel coordinate plots (Inselberg, 1985) are suitable for representation of complex relationships (Figure 1b). For instance, Fleming et al. (2005) applied the parallel coordinates plot to assist many-objective optimisation during the design of a control system for gas-turbine engines. In a co-occurrence matrix, a rearrangement of rows and columns can reveal the clusters of highly interconnected components (van Beek et al., 2010). Finally, relationships could be represented using links that are invisible and yet implied (Spence, 2001). Through multiple view coordination technique (Baldonado et al., 2000) linked elements can be connected not through visible edges but by synchronised highlighting using the same colour, for instance.

\subsection{Hierarchies}

Simon defines hierarchy as "a system that is composed of interrelated subsystems, each of the latter being, in turn, hierarchic in structure until we reach some lowest level of elementary subsystem" and argues that hierarchy is one of the fundamental features of complex systems (Simon, 1965). Understanding hierarchy of a system is essential for design participants, as it provides a structural overview of a system and helps to partition it into subsystems and components, which alleviates sensemaking of a system. Hierarchies in design represent not only product architecture, but functional decomposition (Hehenberger, 2014) and the history of design decisions (Bracewell et al., 2009). Moreover, the design process itself could be viewed as a hierarchy. For example, Hubka (1976) presented a hierarchical model of design process activities with design stages (e.g. planning, conceptualisation, detailing) at the top level and elementary operations (e.g. comparison, analysis, reading) at the bottom level.

Tree diagrams (Figure 2a) are common visual representations of hierarchies. In addition to Gestalt principles of continuity, closure and connectedness, which are used in generic entity-relationship diagrams, tree diagrams benefit from the similarity principle when showing entities that belong to the same level of hierarchy. One limitation of conventional static tree diagrams is that it becomes hard to navigate the tree when the number of elements becomes large, similarly to entity-relationship 
diagrams (Maier et al., 2014). Since designers continuously have to switch between different levels of abstraction, more flexible and interactive representations of hierarchies are needed.

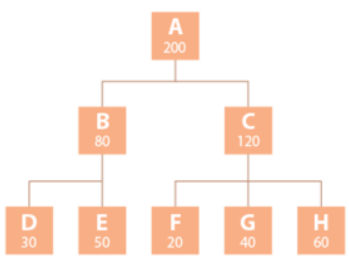

a) tree diagram

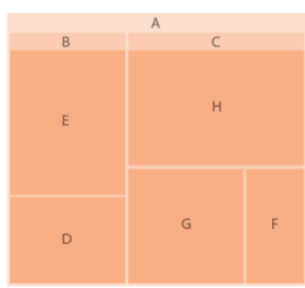

b) treemap diagram

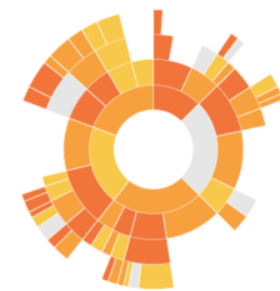

c) sunburst diagram

Figure 2. Visual representations of hierarchies (images from Ribecca, 2019)

Collapsible tree diagram (Plaisant et al., 2002) allows users to expand or collapse nodes to provide the required level of overview or detail on demand. Moreover, sunburst diagram (Figure 2c) (Stasko and Zhang, 2000) or a treemap diagram (Figure 2b) (Shneiderman, 1992) were developed to reflect the quantitative proportions of system entities in addition to hierarchy.

\subsection{Patterns}

Another way of reducing the perceived complexity of a system is through highlighting its intrinsic patterns (Card et al., 1999). Being able to see patterns (most often in quantitative data), such as clusters, classes and trends in data allows designers to detect commonalities among a large number of elements, inspect outliers and find other insights about the designed system. Based on the Gestalt principle of proximity and similarity, patterns in data can be displayed in many ways: as clusters (Figure 3a) or as correlation trends in a scatter plot (Figure 3b), or as the regions of various intensity in a heatmap diagram (Figure 3c).

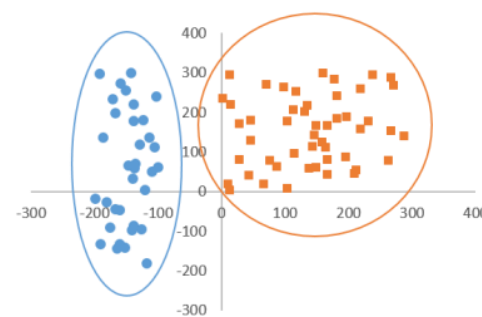

a) scatter plot (clusters)

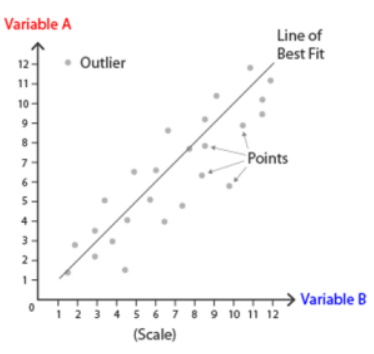

b) scatter plot (trends)

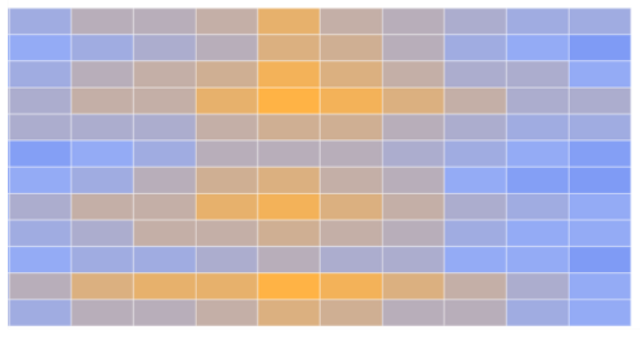

c) heatmap diagram

Figure 3. Visual representations of patterns b) and c) images from Ribecca (2019)

For example, Feldt et al. (2013) apply heatmap diagrams to perform quality checks in the software, while Yan et al. (2012) propose to use scatter plot to visualise clusters of similar design concepts. In these studies, visualisation techniques such as highlighting, filtering and multiple view, aim to facilitate the exploration of patterns in complex information.

\subsection{Processes}

While relationships and hierarchies can be used to describe an architecture of a system, a designer has to have a dynamic view that shows how the system and its elements change over time. Without the temporal aspect, the representation of a complex system is "incomplete" (Cilliers, 1998). Likewise, Simon distinguishes between two types of system descriptions: state and process descriptions (Simon, 1965).

Conventional visualisations, such as flow charts (Figure 4a), are limited in their ability to represent processes. Following the Gestalt principle of continuity, changes in a system are typically represented by an "arrow" symbol, that signifies, for instance, exchange of materials, energy and information (Pahl et al., 2007) or changing from one state to another. Conversely, in information visualisations, using interactivity and rearrangement techniques enables an "enriched vocabulary" to express processes in design (Ware, 
2012). For instance, in Sankey diagrams (Riehmann et al., 2005) exchange of energy between components can be visualised as a set of pixels moving into the same direction (Figure 4b), thereby applying the common fate Gestalt principle. In another example, Gantt charts (Figure 4c), which are one of the prevalent process visualisations in design (Keller et al., 2006), are augmented using information visualisation techniques, such as filtering out finished processes or highlighting the ones that are close to the deadline.

(A)

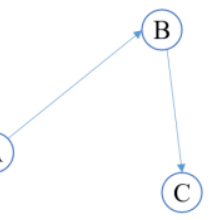

a) flow chart

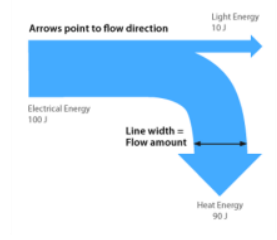

b) Sankey diagram

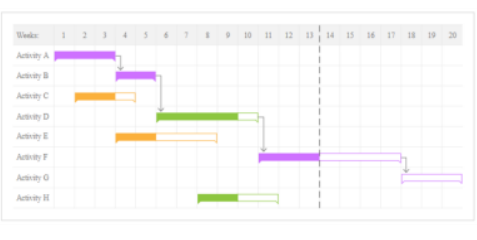

c) Gantt chart

Figure 4. Visual representations of processes (b) and c) from Ribecca (2019)

\section{Implications}

Connecting information visualisation with system features and design tasks is one of the initial steps towards theory-building about the mechanisms that allow information visualisations to support design. First, by reviewing systems theory and design research literature, we derived fundamental systems features that are representable by symbolic representations. Second, by reviewing design research literature, we determined studies that use computer-supported interactive information visualisations. Finally, using existing taxonomies of information visualisations and Gestalt principles, we connected information visualisations to fundamental systems features they represent when supporting design tasks. As such, the contribution of this work is threefold. First, as there are a large number of studies that focus on the development of information visualisations to support similar design tasks, this paper aims to make future researchers avoid duplicate efforts in developing these visual methods. When developing novel visual approaches to support specific design tasks, readers can consider a set of existing visualisations listed in Table 2 concerning such a task. Second, by combining desired systems features that need to be represented when performing specific design tasks, one can use information visualisations that represent similar systems features. For instance, when performing traceability and change propagation analysis, the capability of the visualisation to show relationships between system entities (e.g. components) is crucial. Thus, information visualisations that are suitable for representation of relationships, such as cooccurrence matrices and network diagrams, are frequently used for tracing connections between system entities (e.g. between requirements and validation tests). In another example, when supporting modularisation tasks, visualisations that represent hierarchy and patterns (e.g. co-occurrence matrices and treemap diagrams) are appropriate. Finally, design researchers can find novel applications of information visualisations in design where visualising similar system features is required. For instance, both structural and functional decomposition in a product can be visualised using the same systems features and the same visualisations, such as hierarchical collapsible trees.

\section{Conclusions}

Designers handle large amounts of heterogeneous information when designing a product. One way of visualising such information is to use computer-supported interactive information visualisations, which facilitate user cognition of complex information. While there are studies that propose the use of information visualisations in product design, very few of them focus on systemising such research and no research that explicitly link information visualisations for design support to underlying visual principles. Thus, in this paper, we review literature from systems theory, information visualisation and design research to connect fundamental systems features, information visualisations and design tasks. Four fundamental systems features are discussed: relationships, hierarchies, patterns and processes. For each systems feature, we touch upon its established visual representations, suitable information visualisations and underlying Gestalt principles, and visualisation techniques that aid to convey the respective feature. The performed mapping permits gaining a better understanding of why certain information visualisations are beneficial to support certain design tasks. Furthermore, the system 
features defined in the paper can serve as a reference when developing novel design support methods using computer-supported information visualisations.

\section{Acknowledgements}

Funding has been received from the European Union (EU) Horizon 2020 Framework Programme for Research and Innovation under Grant Agreement No. 770420 - EURITO.

\section{References}

Baldonado, M.Q.W., Woodruff, A. and Kuchinsky, A. (2000), "Guidelines for using multiple views in information visualization", Workshop on Advanced Visual Interfaces, February 2013, pp. 110-119.

van Beek, T.J., Erden, M.S. and Tomiyama, T. (2010), "Modular design of mechatronic systems with function modeling", Mechatronics, Vol. 20 No. 8, pp. 850-863. https://doi.org/10.1016/j.mechatronics.2010.02.002

Buur, J. and Andreasen, M.M. (1990). "Design models in mechatronic product development". Design Studies, Vol. 10 No. 3, 155-162. https://doi.org/10.1016/0142-694X(89)90033-1

Bracewell, R. et al. (2009), "Capturing design rationale", CAD Computer Aided Design, Elsevier, Vol. 41 No. 3, pp. 173-186. https://doi.org/10.1016/j.cad.2008.10.005

Bresciani, S. (2019), "Visual Design Thinking: A Collaborative Dimensions framework to profile visualisations", Design Studies, Vol. 63, pp. 92-124. https://doi.org/10.1016/j.destud.2019.04.001

Browning, T.R. (2009), "The many views of a process: Toward a process architecture framework for product development processes", Systems Engineering, Vol. 12 No. 1, pp. 69-90. https://doi.org/10.1002/sys.20109

Card, S.K., Mackinlay, J. and Shneiderman, B. (1999), Readings in Information Visualization: Using Vision to Think, Morgan Kaufmann Publishers. https://doi.org/10.5555/300679.300826

Chandrasegaran, S.K. et al. (2013), "The evolution, challenges, and future of knowledge representation in product design systems", CAD Computer Aided Design, Vol. 45 No. 2, pp. 204-228. https://doi.org/10. 1016/j.cad.2012.08.006

Chen, C. and Yu, Y. (2000), "Empirical studies of information visualization: a meta-analysis", International Journal of Human-Computer Studies, Vol. 53, pp. 851-866. https://doi.org/10.1006/ijhc.2000.0422

Cilliers, P. (1998), Complexity and Posmodernism. Understanding Complex Systems. Taylor \& Francis, London. https://doi.org/10.4324/9780203012253

Clarkson, J., Simons, C. and Eckert, C. (2004), "Predicting change propagation in complex design", Journal of Mechanical Design, Vol. 126 No. 5, pp. 788-797. https://doi.org/10.1115/1.4027495

Crawley, E., Cameron, B. and Selva, D. (2015), System Architecture: Strategy and Product Development for Complex Systems, Prentice Hall Press.

Demian, P. and Fruchter, R. (2006), "Finding and understanding reusable designs from large hierarchical repositories", Information Visualization, Vol. 5, pp. 28-46. https://doi.org/10.1057/palgrave.ivs.9500114

Elbeltagi, E. et al. (2017), "Visualized strategy for predicting buildings energy consumption during early design stage using parametric analysis", Journal of Building Engineering, Vol. 13, pp. 127-136. https://doi.org/10. 1016/j.jobe.2017.07.012

Eppler, M.J. and Kernbach, S. (2016), "Dynagrams: Enhancing design thinking through dynamic diagrams", Design Studies, Vol. 47, pp. 91-117. https://doi.org/10.1016/j.destud.2016.09.001

Eppler, M.J. and Platts, K.W. (2009), "Visual Strategizing. The Systematic Use of Visualization in the StrategicPlanning Process", Long Range Planning, Vol. 42 No. 1, pp. 42-74. https://doi.org/10.1016/j.lrp.2008.11.005

Feldt, R. et al. (2013), "Supporting software decision meetings: Heatmaps for visualising test and code measurements", 39th Euromicro Conference Series on Software Engineering and Advanced Applications, SEAA 2013, pp. 62-69.

Fleming, P.J., Purshouse, R.C. and Lygoe, R.J. (2005), "Many-Objective Optimization: An Engineering Design Perspective", International Conference on Evolutionary Multi-Criterion Optimization, pp. 14-32.

Goldschmidt, G. (1991), "The Dialectics of Sketching”, Creativity Research Journal, Vol. 4 No. 2, pp. 123-143. https://doi.org/10.1080/10400419109534381

Gumpinger, T. et al. (2011), "A visualization concept for supporting module lightweight design", 18th International Conference on Engineering Design (ICED 11), Vol. 10, pp. 349-359.

Hashem, I.A.T. et al. (2015), "The rise of 'big data' on cloud computing: Review and open research issues", Information Systems, Vol. 47, pp. 98-115. https://doi.org/10.1016/j.is.2014.07.006

Heer, J., Bostock, M. and Ogievetsky, V. (2010), "A tour through the visualization zoo", Communications of the ACM, Vol. 53 No. 6, p. 59. https://doi.org/10.1145/1743546.1743567

Hehenberger, P. (2014), "Perspectives on hierarchical modeling in mechatronic design", Advanced Engineering Informatics, Vol. 28 No. 3, pp. 188-197. https://doi.org/10.1016/j.aei.2014.06.005 
Henderson, K. (1998), On Line and On Paper: Visual Representations, Visual Culture, and Computer Graphics in Design Engineering, MIT Press Cambridge, MA, USA, p. 256.

Hubka, V. (1976), Theorie Der Konstruktionsprozesse: Analyse Der Konstruktionstätigkeit, Springer-Verlag, Berlin Heidelberg. https://doi.org/10.1007/978-3-642-81035-0

Idrissov, A., Parraguez, P. and Maier, A.M. (2019), "Tracing Paths and Connecting Multiple Design Domains: An Information Visualisation Approach to Product Architecture Modelling", International Conference on Engineering Design (ICED'19), Vol. 1, pp. 3021-3030.

Inselberg, A. (1985), "The plane with parallel coordinates", The Visual Computer, Springer-Verlag, Vol. 1 No. 4, pp. 69-91. https://doi.org/10.1007/BF01898350

Josefsson, E. (2014), Multi-viewed Visualization of Modularity for Product Line Management, Ericsson AB.

Keim, D.A. (2002), "Information visualization and visual data mining", IEEE Transactions on Visualization and Computer Graphics, Vol. 8 No. 1, pp. 1-8. https://doi.org/10.1109/2945.981847

Keller, R. et al. (2005), "Visualising Change Propagation", International Conference on Engineering Design (ICED’05), pp. 1-89.

Keller, R. et al. (2006), "Two sides of the story: Visualising products and processes in engineering design", International Conference on Information Visualisation, pp. 362-367.

Koffka, K. (2013), Principles of Gestalt Psychology, Taylor \& Francis, Routledge. https://doi.org/10.4324/ 9781315009292

Langelier, G., Sahraoui, H. and Poulin, P. (2005), "Visualization-based analysis of quality for large-scale software systems", 20th International Conference on Automated Software Engineering (ASE 2005), pp. 214-223.

Lengler, R. and Eppler, M.J. (2007), "Towards a Periodic Table of Visualization Methods for Management", IASTED International Conference on Graphics and Visualization in Engineering (GVE 2007), pp. 83-88.

Maier, A.M. et al. (2014), "Towards Diagram Understanding: A Pilot-Study Measuring Cognitive Workload Through Eye-Tracking", International Conference on Human Behaviour in Design, pp. 1-6.

Maier, M. and Rechtin, E. (2000), The Art of Systems Architecting, CRC Press.

Martinec, T. and Pavković, N. (2014), "Visualization of information traceability in product development", International Design Conference (DESIGN 2014), pp. 1831-1842.

Merten, T., Jüppner, D. and Delater, A. (2011), "Improved representation of traceability links in requirements engineering knowledge using Sunburst and Netmap visualizations", International Workshop on Managing Requirements Knowledge (MaRK11), pp. 17-21.

Oxman, R. (2006), "Theory and design in the first digital age", Design Studies, Vol. 27 No. 3, pp. 229-265.

Pahl, G. et al. (2007), Engineering Design: A Systematic Approach, Springer-Verlag, London. https://doi.org/ 10.1007/978-1-84628-319-2

Pavković, N. et al. (2013), "Facilitating design communication through engineering information traceability", Artificial Intelligence for Engineering Design, Analysis and Manufacturing, Vol. 27 No. 2, pp. 105-119. https://doi.org/10.1017/S0890060413000012

Plaisant, C., Grosjean, J. and Bederson, B.B. (2002), "SpaceTree: Supporting exploration in large node link tree, design evolution and empirical evaluation", IEEE Symposium on Information Visualization, pp. 57-64.

Rechtin, E. (1991), Systems Architecting: Creating and Building Complex Systems, Lebanon, USA, Prentice Hall.

Ribecca, S. (2015), The Data Visualisation Catalogue. Available at: http://datavizcatalogue.com/

Riehmann, P., Hanfler, M. and Froehlich, B. (2005), "Interactive sankey diagrams", IEEE Symposium on Information Visualization, pp. 233-240. https://doi.org/10.1109/INFVIS.2005.1532152

Shneiderman, B. (1992), "Tree visualization with tree-maps: 2-d space-filling approach", ACM Transactions on Graphics, Vol. 11 No. 1, pp. 92-99. https://doi.org/10.1145/102377.115768

Shneiderman, B. (2003), "The Eyes Have It: A Task by Data Type Taxonomy for Information Visualizations", The Craft of Information Visualization, pp. 364-371. https://doi.org/10.1109/VL.1996.545307

Simon, H.A. (1965), "The architecture of complexity”, General Systems, Vol. 10, pp. 63-76.

Spence, R. (2001), Information Visualization, Addison-Wesley, New York.

Stasko, J. and Zhang, E. (2000), "Focus+context display and navigation techniques for enhancing radial, spacefilling hierarchy visualizations", IEEE Symposium on Information Visualization, pp. 57-65.

Steward, D.V. (1981), "Design Structure System: a Method for Managing the Design of Complex Systems", IEEE Transactions on Engineering Management, Vol. EM-28 No. 3, pp. 71-74.

Ullman, D.G. (1992), “A taxonomy for mechanical design”, Research in Engineering Design, Vol. 3 No. 3 , pp. 179-189. https://doi.org/10.1007/BF01580519

Ware, C. (2012), Information Visualization, Morgan Kaufmann.

De Weck, O.L. et al. (2011), Engineering Systems: Meeting Human Needs in a Complex Technological World, 1st ed., MIT Press, Cambridge, MA.

Yan, X. et al. (2012), "A Work-Centered Visual Analytics Model to Support Engineering Design with Interactive Visualization and Data-Mining", 45th IEEE Hawaii International Conference on System Sciences, pp. 1845-1854. 